\title{
CONTACTLESS MEASUREMENT OF RECTILINEARITY OF AN ELONGATED OBJECT BASED ON THE EXAMPLE A CRANE RAIL
}

\author{
Kazimierz Ćmielewski ${ }^{1}$, Janusz Kuchmister ${ }^{1}$, Piotr Gołuch ${ }^{1}$, \\ Henryk Bryś ${ }^{2}$ \\ 1) Wrocław University of Environmental and Life Sciences, Poland \\ 2) Cracow University of Technology, Poland
}

\begin{abstract}
The common aim of engineering surveys is to determine deviations from rectilinearity for elongated objects. We have developed a number of methods for measuring points that represent an elongated object. These are the constant straight (optical, laser, mechanical-string) method, the trigonometric method, geometric levelling method, photogrammetric methods and terrestrial laser scanning. When taking these measurements, it is crucial to have a direct access to the survey points of the measured object. Factors impeding the measurements include: adverse lighting conditions, vibration, dust, refractory effects, lack of direct access to the survey points, etc.

The authors have developed a measurement methodology and designed a measuring set for taking measurements that enable to determine the location of survey points on an elongated object.

The measurement is based on the constant straight method and the measuring set consists of the horizontal levelling staff and two laser pointers. The measuring set relies on the angular intersection (fixed angle) method. Intersection occurs when two laser beams meet. To determine the location of the survey point indicated by the mentioned laser beams, we used levelling staff readings taken with the surveying instrument that establishes the reference constant straight.

Experimental studies carried out in the laboratory and in the field helped to determine the accuracy of measurements taken with the designed measuring set (the accuracy was below $\pm 1 \mathrm{~mm}$ ) and revealed that this accuracy is comparable to accuracies achieved with famous classical measurement methods.
\end{abstract}

Keywords: elongated object, laser instrument, crane rail 


\section{Methods of measuring elongated buildings}

Elongated objects include: dam crests, water gates and weirs, machines and device guides, crane rails, retaining walls, etc. (Fig. 1).

The choice of method and surveying equipment depend on the required measurement accuracy imposed by the guidelines and industry standards (Ministerstwo Hutnictwa i Przemysłu Maszynowego, 1982). The measurement methods can be divided into direct and indirect methods and methods of measurement in the horizontal plane $(X Y)$, vertical plane $(H)$ or spatial measurement (XYH) (Bryś et al. 2008; Gocał, 2010; Janusz, 1975; Mora, 1998; Pachuta, 1980).

The measurement methods that can be used in the horizontal plane $(X Y)$ and which require a direct and full access to the survey points representing the researched object include: the constant straight and the polar method. Measurements in the vertical plane are taken using geometric or trigonometric leveling. Measurements in both planes are performed simultaneously using the trigonometric method.

A limited access to the surveyed object imposes the necessity of using direct methods of measurement such as the photogrammetric method, laser scanning, angular intersection, linear intersection or angular-linear intersection. When performing measurements with these methods, apart from classical surveying instruments, additional devices may also be used (e.g. target discs, target points) (Bryś et al., 2008; Ćmielewski, 2007; Gocał, 2010; Janusz, 1975; Mora, 1998; Pachuta, 1980).
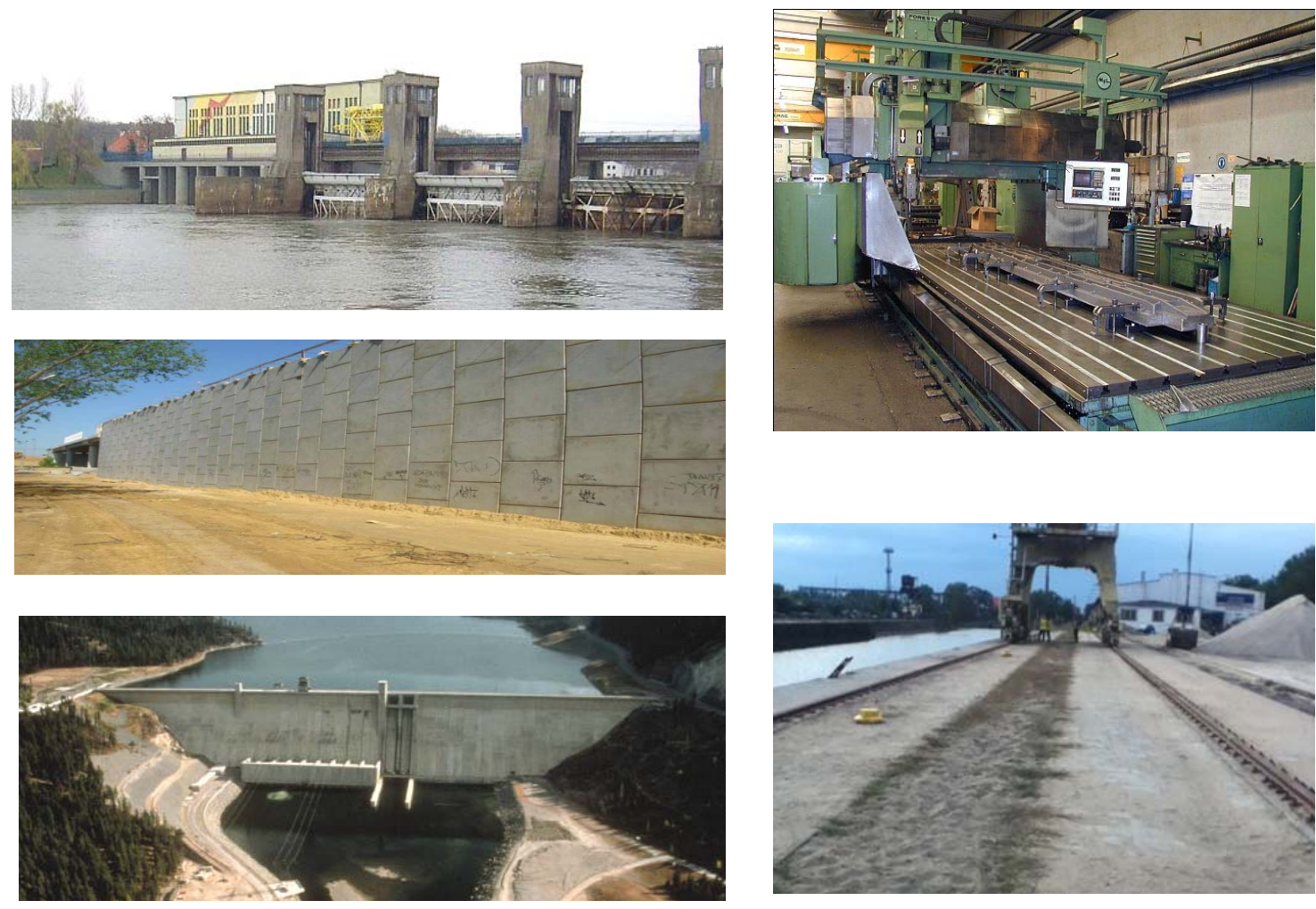

Fig. 1. Examples of elongated engineering objects: a) weir, b) retaining wall, c) dam, d) machine bed, e) crane rail 


\section{Comparison of classical methods of measurement with the contactless method}

The idea of measuring rectilinearity of an elongated object is presented using the crane rail example. Traditional measurements of rectilinearity are related to measurements of the rail axis deviation from the reference straight in the selected survey points.

In the classical method of the constant straight (Fig. 2A), distances between the reference straight (designated by the vertical reference plane) and the edge of the crane track rail " $d_{T}$ " are measured on the staff. The staff is placed horizontally on the rail, and perpendicularly to the reference straight. The determined deviation $d_{L}$ is described with the formula (1).

Figures $2 \mathrm{~B}$ and $2 \mathrm{C}$ present the idea of the contactless measuring method with a laser device installed on the staff. The structural basis of the measurement set is to make intersection from the base by means of two laser diodes (Toshiba, 2002), when intersecting angles $\alpha_{1}$ and $\alpha_{2}$ are fixed (Fig. 2B). The instrument can be installed permanently in any place of the staff (Figure 2B). When measuring deviations, it is important to maintain a constant distance " $w$ " of "laser triangle", which is used to designate the measured deviation $d_{L}$ based on the formula (2), (3), (4) and (5). A special case is when the base of the instrument is attached to the staff foot (Fig. 2C). Then, the value $O_{D}=0.0 \mathrm{~mm}$ and the formula for the calculation of the deviation $d_{L}$ becomes (6).

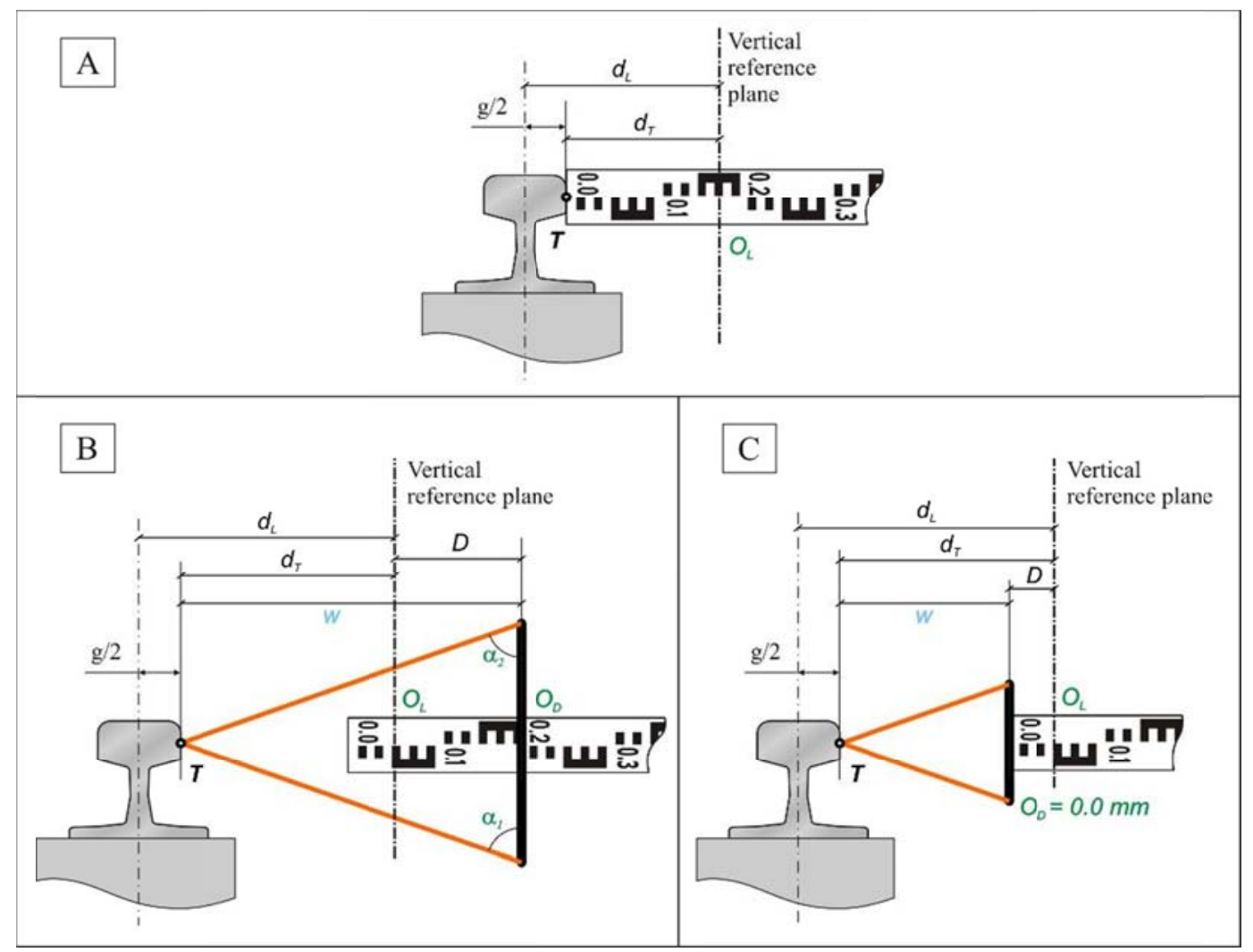

Fig. 2. The principle of distance measurement from a vertical reference plane to the rail axis

A. The principle of measurement with the classical method; $B$. The principle of measurement with the contactless method and using the laser device attached to the staff;

C. The principle of measurement with the contactless method and using the laser device attached to the staff foot. 


$$
\begin{aligned}
& d_{L}=O_{L}+\frac{g}{2} \\
& d_{L}=d_{T}+\frac{g}{2} \\
& D=O_{D}-O_{L} \\
& d_{T}=w-D \\
& d_{L}=w-\left(O_{D}-O_{L}\right)+\frac{g}{2} \\
& d_{L}=w+O_{L}+\frac{g}{2}
\end{aligned}
$$

Symbols that appear in Figures 2 to 5 and the formulas (1) to (6):

$d_{L}$ - deviation of the rail axis from a vertical reference plane;

$d_{T}$ - the distance of the lateral surface of the rail head from a vertical reference plane;

$g$ - rail head width;

$O_{L}$ - reading of the vertical reference plane location on the staff;

$O_{D}$ - reading of the laser device base location on the staff;

$D$-the distance between the location of the laser device base and the vertical reference plane;

$w$ - height of the "laser triangle".

\section{Construction of the instrument and the measurement method}

The laser device (Fig. 3) has a body in the form of the load bar (1), which has the positioning and levelling element at the bottom (6). On the centring element two micrometric tables (3) are located to shift the load bar in two mutually perpendicular directions, along $b-b$ and $c-c$ axis. On the load bar attached to the cross micrometric table (3) three laser transmitters (2) and two tubular levels (5) are installed.

Laser beams from two laser transmitters (2), fixed to the ends of the load bar, aim for angular intersection under the established (during calibration) identical angles $\alpha$.

The third laser transmitter (2) located in the middle of the load bar is used to control the perpendicularity of the levelling staff (4) to the line of sight of the geodetic instrument that realizes the constant reference straight $(\boldsymbol{P}-\boldsymbol{K})$. The radius of this laser transmitter ( $c-c$ axis) should be perpendicular to the load bar axis $(b-b)$. The laser device in its upper part has a levelling staff installed horizontally (4) so that its longitudinal axis is perpendicular to the load bar axis $(b-b)$. The set of two tubular levels (5) enables to set the $v$-v axis of the laser instrument vertically. The design of the instrument provides for the mutual perpendicularity of $v-v, c-c$, and $b-b$ axes.

Before measurements measuring sections $\left(L_{i}-L_{i}\right)$ need to be determined and location of points $\boldsymbol{P}$ and $\boldsymbol{K}$ (instrument and target disc stations) has to be signalled, while the reference constant straight is determined (Fig. 3B and Fig. 4).

Over the points $\boldsymbol{P}$ and $\boldsymbol{K}$ one should set up a geodetic instrument and the target disc. In the measuring section $L_{i}-L_{i}$ the measuring device needs to be set in such a way that the laser dot images observed on the surface of the measured element (Figure 5), are near the indicated measuring section. Before starting measurements, the $v-v$ axis needs to be set vertically by using leveling screws and by observing the level indications (Fig 3A and Fig. 4A). Then, using the screws of micrometric tables, one must make the laser dots coincide and check whether the third diode dot is also in the measuring section (Fig. 5). 


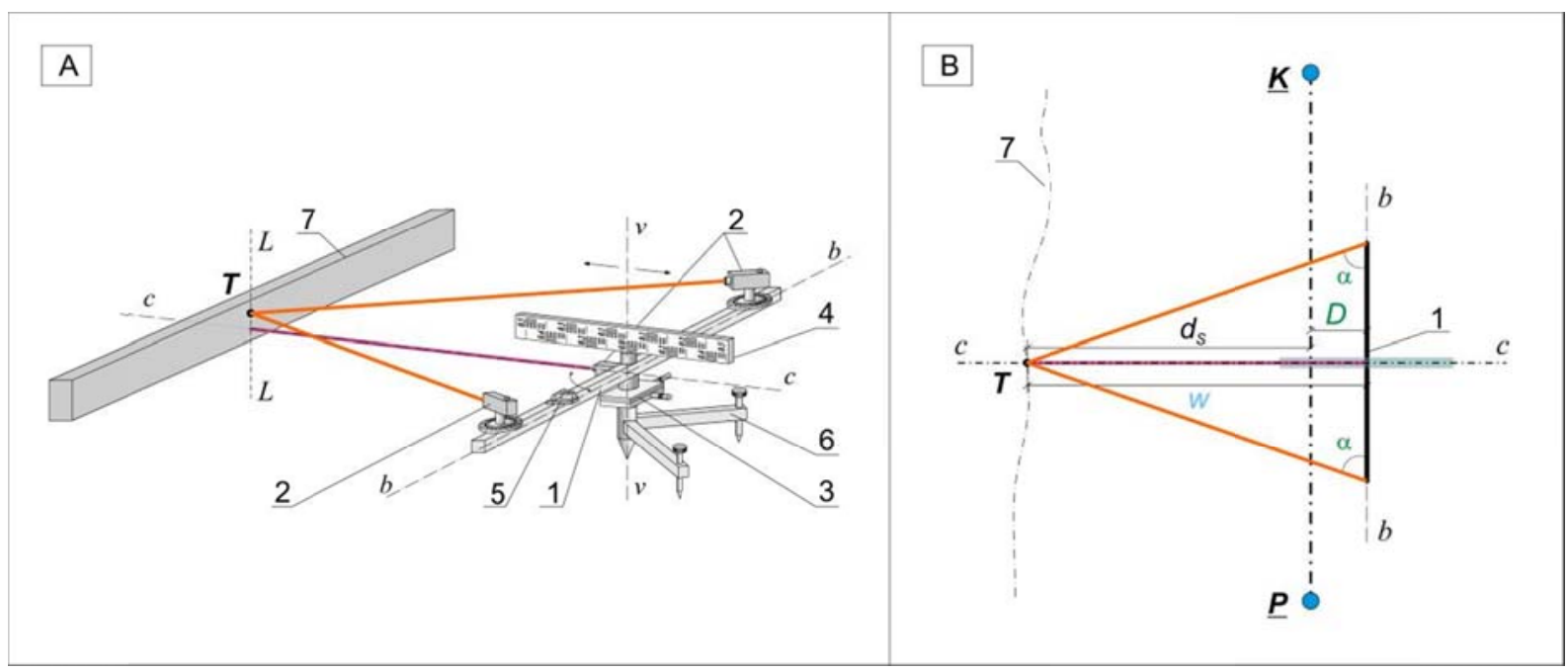

Fig. 3. The gist of the construction and the method of measurements; with the laser instrument: A. Construction of the laser instrument; B. The measurement scenario. Where: 1-the body of the instrument (the load bar); 2-laser transmitter; 3-micrometric table; 4-levelling staff; 5 - tubular levels; 6-positioning and levelling element; 7-examined elongated object; $b$-b-load bar axis (1); $v$-v-vertical axis of the laser instrument; $c$-c-axis perpendicular to the load bar (1), located in the same plane as $v$-v axis; $\alpha$-angle between the radius of the laser transmitter and $b-b$ the load bar axis base; $\boldsymbol{T}$ - a point located in the measuring section $L-L ; \boldsymbol{P}, \boldsymbol{K}$-points of the reference straight.

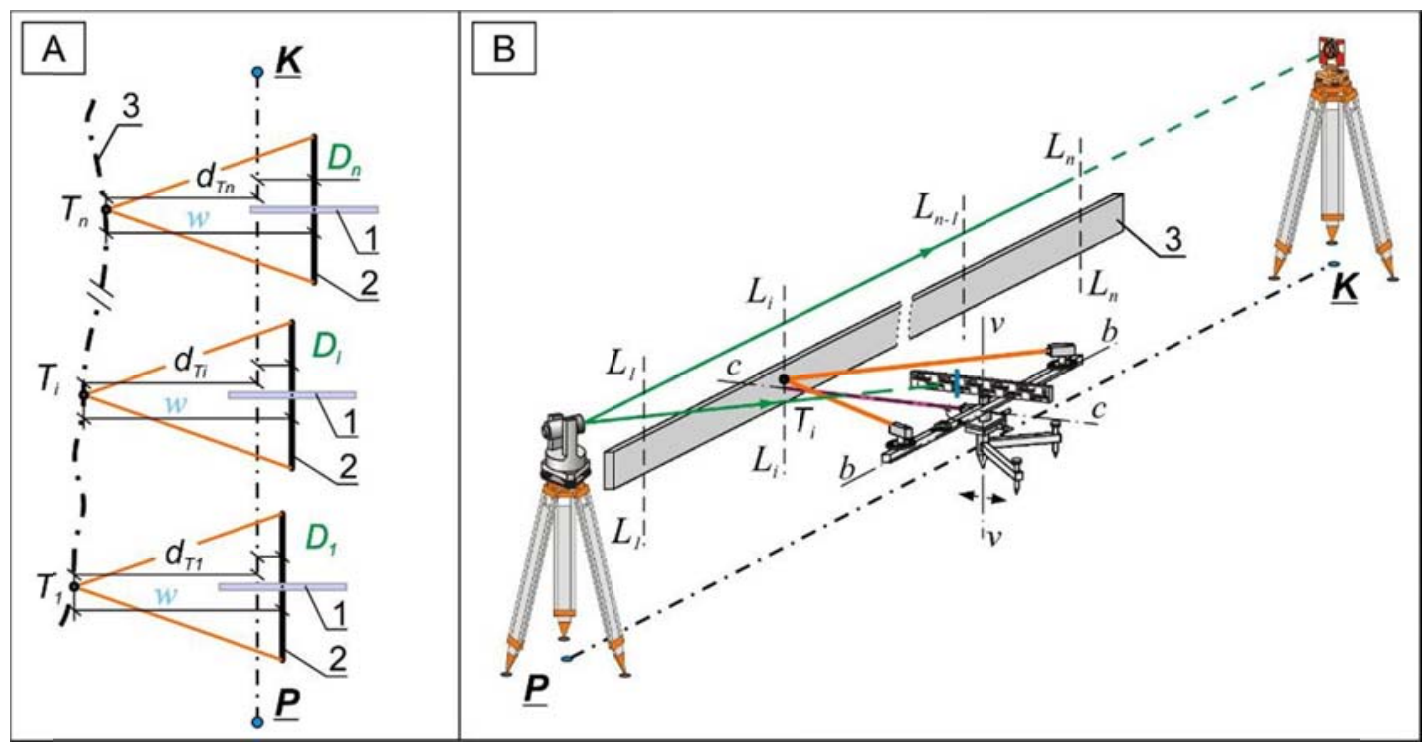

Fig. 4. Rectilinearity measurement of an elongated object with the laser instrument:

A. The gist of the measurement; B. Example of performed measurements.

Where: 1-levelling staff; 2-the body of the instrument (the load bar); 3-investigated elongated object; $b$ - $b$-axis of the load bar; $v$-v-vertical axis of the laser instrument; $c$-c-axis perpendicular to the load bar; $\boldsymbol{T}_{\boldsymbol{i}}$-a point in the measuring section $L_{i} L_{i} ; \boldsymbol{P}, \boldsymbol{K}$-points on the reference straight. 


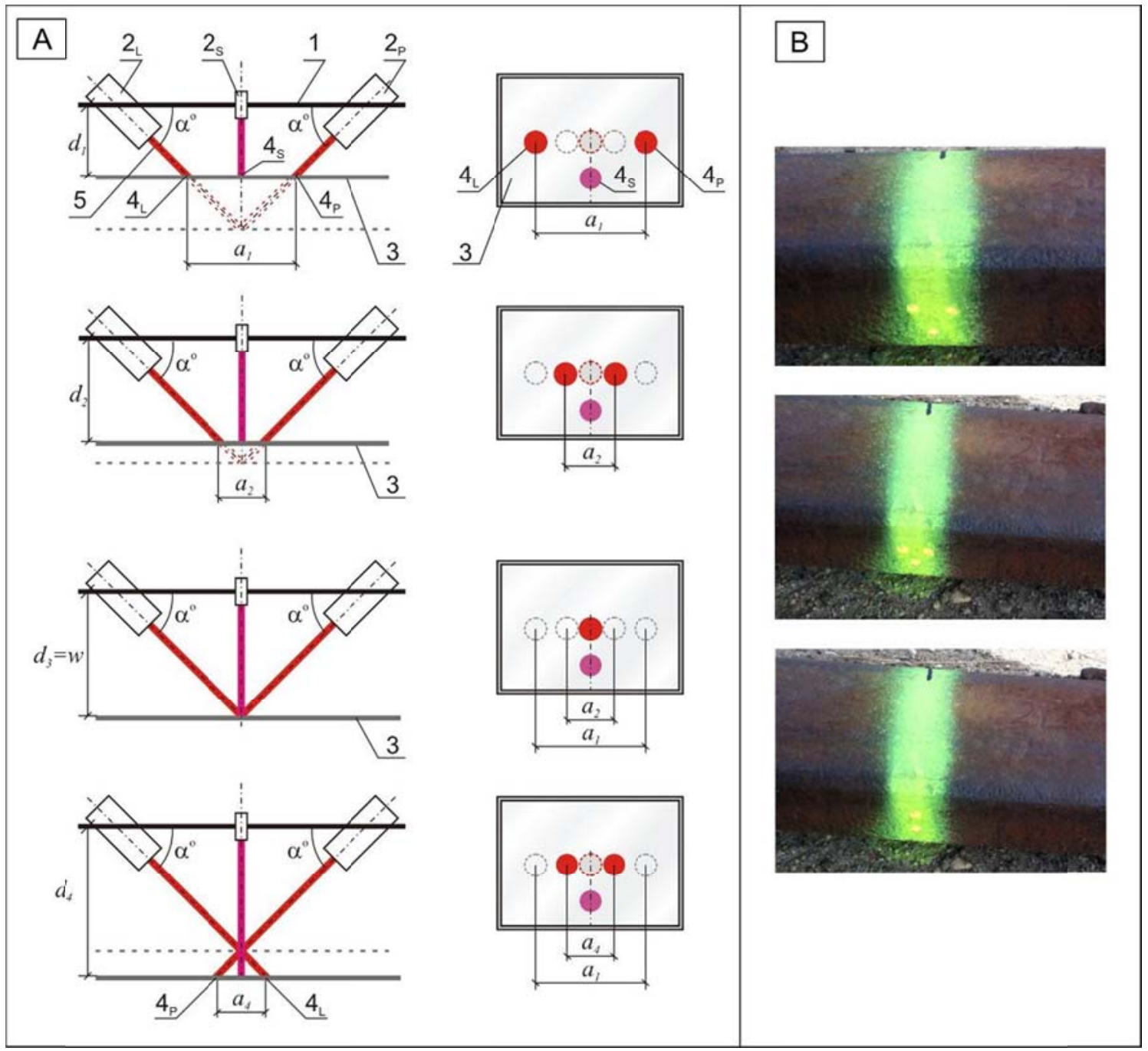

Fig. 5. The position of the laser dots in the measured section:

A. Possible cases of mutual position of laser spots depending on the distance between the base of the laser device and the area of the measured element $d_{i ;}$; $\mathrm{B}$. Image presenting the position of the laser dots on the lateral surface of the investigated crane rail.

Where: 1-the load bar; $2_{\mathrm{L}}, 2_{\mathrm{P}}, 2_{\mathrm{S}}$-laser transmitters: left, right and middle; 3 -the test object; $4_{\mathrm{L}}, 4_{\mathrm{P}}, 4_{\mathrm{S}}$-traces (left, right, and middle) of a laser beam on the surface of the test object; 5 the laser beam; $\alpha$ is the angle between the transmitter laser radius and the load bar axis; $a_{1}$, $a_{2}, a_{3}, a_{4}$-the distance between the traces of the left and right laser beam on the surface of the test object; $d_{1}, d_{2}, d_{3}, d_{4}$-the distance between the laser transmitters and the surface of the test object; $w$-height of the "laser triangle".

\section{The results of experimental research}

Experimental research works were carried out in the Wrocław City Port. On the 40metre section of the crane rail, at every $5 \mathrm{~m}$ we determined 8 measuring sections. Vertical reference plane was located along the axis of the rail in such a way that it included points $\boldsymbol{P}$ and $\boldsymbol{K}$, above which the theodolite and the target disc were set (centred) during measurements.

The location of the crane rail in the horizontal plane was measured in the traditional way which relies on the theodolite and the horizontal staff. The measurements were taken in a few series in order to control the results and to estimate the average measurement error. 
Then, we measured points located in the same measurement sections of the crane rail using the discussed laser device. In measurements we used the same points of the survey network (reference straight) and the same theodolite.

In order to assess the internal consistency and accuracy of the results of measurement performed with the designed laser device, four series of measurements were taken.

The accuracy of measurements taken with the laser device was established on the basis of observation pairs, by comparing the averaged results of measurements taken with the traditional method and measurements taken with the laser device. The measurement results and evaluation of their accuracy is shown in Table 1.

Table 1. Averaged measurement results of the rectilinearity of the crane rail axis

\begin{tabular}{|c|c|c|c|c|c|c|c|c|c|c|}
\hline \multicolumn{11}{|c|}{ Alignment survey } \\
\hline \multirow{3}{*}{$\begin{array}{l}\text { Profile } \\
\text { Number }\end{array}$} & \multirow{3}{*}{$\begin{array}{l}\varepsilon \\
\text { na } \\
\text { s. } \\
b\end{array}$} & \multicolumn{7}{|c|}{ by Laser device with ruler } & \multirow{3}{*}{$\begin{array}{l}\text { Classical } \\
\text { method } \\
\text { (C) }\end{array}$} & \multirow{3}{*}{$\begin{array}{c}\text { Difference } \\
v=\mathrm{L}-\mathrm{C}\end{array}$} \\
\hline & & \multicolumn{3}{|c|}{ Face left } & \multicolumn{3}{|c|}{ Face right } & \multirow[b]{2}{*}{$\begin{array}{l}\text { MEAN } \\
\text { (L) }\end{array}$} & & \\
\hline & & $\begin{array}{c}\text { Number of } \\
\text { measure- } \\
\text { ments }\end{array}$ & Mean & StdDev & $\begin{array}{c}\text { Number of } \\
\text { measure- } \\
\text { ments }\end{array}$ & Mean & StdDev & & & \\
\hline & {$[\mathrm{m}]$} & & {$[\mathrm{mm}]$} & [mm] & & {$[\mathrm{mm}]$} & [mm] & {$[\mathrm{mm}]$} & {$[\mathrm{mm}]$} & {$[\mathrm{mm}]$} \\
\hline 1 & 5 & 4 & 460.8 & 0.3 & 4 & 459.7 & 0.0 & 460.3 & 458.5 & -1.8 \\
\hline 2 & 10 & 4 & 460.1 & 0.5 & 4 & 461.3 & 0.5 & 460.7 & 462.0 & 1.3 \\
\hline 3 & 15 & 4 & 460.0 & 0.5 & 4 & 459.8 & 0.3 & 459.9 & 460.0 & 0.1 \\
\hline 4 & 20 & 4 & 460.3 & 0.3 & 4 & 461.7 & 0.0 & 461.0 & 461.0 & 0.0 \\
\hline 5 & 25 & 4 & 461.7 & 0.0 & 4 & 461.3 & 0.5 & 461.5 & 462.0 & 0.5 \\
\hline 6 & 30 & 4 & 459.6 & 0.3 & 4 & 459.5 & 0.3 & 459.5 & 457.5 & -2.0 \\
\hline 7 & 35 & 4 & 460.0 & 0.5 & 4 & 460.5 & 0.3 & 460.2 & 462.0 & 1.8 \\
\hline 8 & 40 & 4 & 460.6 & 0.6 & 4 & 462.6 & 0.3 & 461.6 & 462.0 & 0.4 \\
\hline & & & & & & The $\mathrm{m}$ & neasur & ment & accuracy & \pm 0.9 \\
\hline
\end{tabular}

$$
m_{d}=\sqrt{\frac{\sum v^{2}}{2 n}}
$$

The accuracy analysis of measurements taken with the traditional method indicates that the average error of a typical observation was $\pm 0.8 \mathrm{~mm}$. The average error of a typical observation for measurements taken with the laser device was \pm 0.4 $\mathrm{mm}$ The calculated average error of a single measurement (formula 7) on the basis of pairs of observations was $m_{d}= \pm 0.9 \mathrm{~mm}$ (Table 1).

\section{Final conclusions}

The research works that were undertaken allow us to formulate the following conclusions and final remarks:

- the proposed method of the contactless rectilinearity measurement features the measurement accuracy comparable to the traditional measurement method (accuracy at the level of $1 \mathrm{~mm}$ ); 
- measurement time in the contactless method is comparable to the measurement time in the classical method;

- the designed measuring device is portable, has a simple construction and is easy to operate when taking non-linear measurements;

- the device needs to be calibrated and standardized;

- the presented device may support other geodetic measurement methods;

- the laser device may also be used for contactless linearity measurements of energized elements and crane rails when the gantry crane is in motion (measurements in places which are safe for people), when the pointing line is not clear or when measuring objects that are rotating.

\title{
References
}

Bryś H., Ćmielewski K. \& Kowalski K. (2008). Zur Methodik der Überwachungsmessungen der Lagegeometrie von Brückenkran-Laufrädern. Allgemeine Vermessungs-Nachrichten, 5/2008, 188-194.

Ćmielewski, K. (2007). Fibre optics and laser technology in high precision measurements of shapes and deformations of engineering objects (in Polish). Wrocław: Zeszyty Naukowe UP we Wrocławiu Nr 551, seria Rozprawy CCXLVI, $242 \mathrm{pp}$.

Gocał J. (2010). Geodezja inżynieryjno przemysłowa. Tom 3. Kraków: Skrypt AGH. Janusz W. (1975). Obsługa geodezyjna budowli i konstrukcji. Warszawa-Wrocław: PPWK.

Ministerstwo Hutnictwa i Przemysłu Maszynowego. (1982). Wytyczne wykonania pomiarów suwnic i jezdni suwnicowych. Zał. nr 15 do instrukcji geodezyjnej resortu przemysłu ciężkiego. Warszawa: Wyd. Przemysłu Maszynowego „WEMA“.

Mora A. S. (1998). Aplicaciones industriales de la topografía (in Spain). MadridCastilla-La Mancha: Colegio Oficial de Ingenieros Técnicos en Topografía, 367 pp.

Pachuta St. (1980). Instrumentoznawstwo geodezyjne - Zastosowanie techniki laserwoej w geodezji. Część I i II. Warszawa: Skrypt WAT.

Toshiba. (2002). Visible laser diodes. Product guide.

\section{Authors:}

\author{
Kazimierz Ćmielewski ${ }^{1)}$, kazimierz.cmielewski@up.wroc.pl \\ Janusz Kuchmister ${ }^{1)}$, janusz.kuchmister@up.wroc.pl \\ Piotr Gołuch ${ }^{1)}$, piotr.goluch@up.wroc.pl \\ Henryk Bryś ${ }^{2}$, hbys@pk.edu.pl \\ 1) Institute of Geodesy and Geoinformatics, \\ Wroclaw University of Environmental and Life Sciences, \\ Grunwaldzka 53, 50-357 Wroclaw, Poland \\ ${ }^{2)}$ Faculty of Environmental Engineering , Cracow University of Technology, \\ Warszawska 24, Poland,
}

